\title{
EDITORIAL
}

\section{A Tax on Virtue}

\author{
Barry Bracewell-Milnes, Banstead
}

Insurance premium tax (IPT) was increased by one percentage point, from 4 per cent to 5 per cent, in the United Kingdom Budget of March 1999. The full-year yield from this increase is estimated at some UK300 million and IPT at 5 per cent will yield over UK1.5 billion. IPT has been the fastest-rising indirect tax in recent years after air passenger duty.

Public response to the increase was muted. The insurance industry had more important things to think about than its customers and mounted no public or effective resistance. Increasing IPT is one of the Government's stealth taxes that pluck the goose with a minimum of hissing. In so far as the increase in IPT was defended or justified, it was presented as a move towards continental levels of tax on insurance.

\section{Excise duties}

The proportion of national income taken in taxation throughout most of the Organization for Economic Cooperation and Development (OECD) is at or near an all-time high. The attempt to raise a given amount of taxation with the minimum of economic damage has been largely superseded by an unprincipled search for taxes that would encounter little political resistance, yielding revenue with a minimum of protest.

United Kingdom IPT is at present charged at 5 per cent on health, home and car insurance. It has been charged at 17.5 per cent on travel insurance since 1998, ostensibly as an anti-avoidance measure: travel firms selling packages of travel and travel insurance were said to be increasing the insurance component (then charged at 4 per cent) at the expense of the travel component (charged at the VAT rate of 17.5 per cent). IPT is not at present charged on life assurance. For some years, medical insurance premiums for the elderly were both entitled to relief from income tax and subject to IPT, which illustrates the level of governmental schizophrenia in this area of policy.
In so far as excise duties, taxes on specific forms of consumer spending, have an economic rationale, they are taxes on activities which are considered in certain quarters to merit fiscal discouragement. Thus duties on drink and tobacco, betting and gaming purport to discourage certain activities or lifestyles; fuel duties, air passenger duty, landfill tax and vehicle excise duties purport to reduce pollution and protect the environment.

In this list, insurance is the odd man out. Although people occasionally over-insure, this is not a vice like drinking too much, nor does it cause congestion or harm the environment. Insurance is not a vice but a virtue. The purchaser of insurance appropriates or privatizes risks which would otherwise have to be borne by his fellow taxpayers. It has often and rightly been said that not insuring is a form of gambling, so that insuring is a form of non-gambling. It is another illustration of governmental schizophrenia that excise duties are levied simultaneously on gambling (betting and gaming duties) and on non-gambling (IPT).

\section{Harmonization}

This policy schizophrenia could well become institutionalized at the level of the European Commission, where there is little interest in fiscal principle beyond harmonizing taxes upwards to protect the interests of high-tax jurisdictions. United Kingdom IPT on travel insurance has already been harmonized with United Kingdom VAT. VAT is at the centre of the Commission's fiscal interests and harmonizing ambitions. It is not difficult to foresee a situation in which the Commission might seek to charge the standard rate of VAT on all forms of insurance including life assurance. Although this would do enormous damage, there is little reason to believe that the interests of the losers would carry much weight with those taking the decisions. 